\title{
ESTADO DA ARTE DAS PESQUISAS DESENVOLVIDAS NO ÂMBITO DO MESTRAdo PROFISSIONAL EM EDUCAÇÃo PROFISSIONAL, TÉCNICA E TECNOLÓGICA NAS TEMÁTICAS ENSINO MÉdIO INTEGRADO, INTERDISCIPLINARIDADE E PROEJA ${ }^{1}$
}

\author{
State of the art of researches carried out under the Professional Master's \\ Degree in professional, technical and technological education in the themes \\ integrated high school, interdisciplinarity and PROEJA
}

\author{
SILVA, Flavio Augusto Pagarine ${ }^{2}$ \\ PRESTES, Liliane Madruga ${ }^{3}$
}

\section{RESUMO}

O presente artigo tem como foco investigar as pesquisas desenvolvidas pelos primeiros egressos do Mestrado Profissional em Educação Profissional, Técnica e Tecnológica (ProfEPT), enfocando as temáticas: ensino médio integrado, interdisciplinaridade e PROEJA. O referido curso vem sendo ofertado pela Rede Federal de Educação Profissional, Científica e Tecnológica (RFEPCT) desde o ano de 2017, e conta com turmas em 36 Instituições Associadas (IAs), ficando a coordenação nacional a cargo do Instituto Federal do Espírito Santo (IFES). A metodologia adotada foi de caráter qualitativo e constou de revisão de literatura e mapeamento das dissertações e respectivos produtos, os quais estão disponibilizados, via web, no Catálogo de dissertações e teses e no Repositório de Objetos Educacionais, ambos da Coordenação de Aperfeiçoamento de Pessoal de Nível Superior (CAPES). O referencial teórico que subsidiou as análises se pautou em autores/as, tais como, Santomé (1998), Frigotto (2008), Ramos (2008, 2010 e 2017), Pombo (2008), Fazenda (2008), Moll (2010), Moura (2012), entre outros/as. Os dados produzidos demonstraram que as pesquisas sobre as temáticas enfocadas ainda são incipientes no âmbito do Mestrado ProfEPT. Ao mesmo tempo, o estudo aponta para a relevância e a potencialidade das dissertações analisadas, cujos produtos educacionais visam à escuta, ao protagonismo e à visibilidade de jovens e adultos no contexto da educação profissional. Além disso, fornecem pistas e inspirações para o desenvolvimento de outras ações visando à promoção da formação onmilateral.

Palavras-chave: Educação profissional. Ensino médio integrado. Interdisciplinaridade.

\begin{abstract}
This article focuses on investigating the research developed by the first graduates of the Professional Master in Professional, Technical and Technological Education (ProfEPT) focusing on the themes of integrated high school, interdisciplinarity and PROEJA. This course has been offered by the Federal Network for Professional, Scientific and Technological Education

\footnotetext{
${ }^{1}$ O texto não foi apresentado ou publicado, anteriomente, em encontros e/ou outros eventos científicos; o projeto de pesquisa que deu origem ao texto passou e foi aprovado pelo Comitê de Ética em Pesquisa; não houve financiamento de órgãos e/ou agências de fomento; é resultante de pesquisa para fins de conclusão de Curso de Mestrado Profissional em Educação Profissional, Técnica e Tecnológica.

${ }^{2}$ Mestrando no Curso de Mestrado Profissional em Educação Profissional, Técnica e Tecnológica ofertado no Instituto Federal de Educação, Ciência e Tecnologia do Rio Grande do Sul - Campus Porto Alegre -IFRS/POA. Bacharel em História pela Universidade Federal do Rio Grande do Sul. Membro do Núcleo de Memória do IFRS- Campus Canoas - RS.

${ }^{3}$ Doutora em Educação. Professora do Programa de Mestrado Profissional em Educação Profissional, Técnica e Tecnológica Instituto Federal de Educação, Ciência e Tecnologia do Rio Grande do Sul - Campus Porto Alegre -IFRS/POA.Coordenadora do Grupo de Pesquisa Caleidoscópio: interseccionando estudos sobre educação, gênero, raça/etnia, classe, geração e mundo do trabalho, o qual integra pesquisadores/as do IFRS e instituições parceiras.
} 
(RFEPCT), since 2017 and has classes in 36 Associated Institutions (IAs), with the national coordination being in charge of the Federal Institute of Espírito Santo (IFES). The methodology adopted was of a qualitative nature and consisted of a literature review and mapping of dissertations and respective products, which are available, via the web, in the Catalog of dissertations and theses and in the Repository of Educational Objects, both from CAPES. The theoretical framework that supported the analyzes was based on authors such as Santomé (1998), Frigotto (2008), Ramos (2008, 2010 and 2017), Pombo (2008), Fazenda (2008), Moll (2010), Moura (2012), among others. The data produced showed that research on the themes focused on is still incipient within the scope of the ProfEPT Masters. At the same time, the study points to the relevance and potential of the analyzed dissertations, whose educational products aim at the listening, the protagonism and the visibility of young people and adults in the context of professional education. In addition, they provide clues and inspirations for the development of other actions aimed at promoting onmilateral training.

Keywords: Professional education. Integrated high school. Interdisciplinarity.

\section{INTRODUÇÃO}

O ano de 2008 representa um marco na história brasileira com a instituição da Rede Federal de Educação Profissional, Científica e Tecnológica (RFEPCT), aprovada pela Lei Federal n. 11.892 de 29/12/2008 (Brasil, 2008) e composta pelos Institutos Federais de Educação, Ciência e Tecnologia, Centros Federais de Educação Tecnológica e Colégio Pedro II. Transcorrida mais de uma década, conforme os dados da Plataforma Nilo Peçanha (BRASIL, 2020), a rede está presente em todos as regiões do país, totalizando 562 unidades em 512 Municípios, ofertando cursos de educação profissional, técnica e tecnológica, desde a Educação Básica até a pós-graduação, em várias modalidades, na forma presencial e a distância. O Instituto Federal de Educação, Ciência e Tecnologia do Rio Grande do Sul (IFRS) é uma das instituições que compõe a RFEPCT e conta com 17 campi situados em diferentes regiões do Rio Grande do Sul.

Quanto aos cursos, a referida Lei de Criação da RFEPCT prevê que a oferta de vagas deverá contemplar o percentual mínimo de 50\% das matrículas na Educação Básica, $20 \%$ das matrículas em cursos de formação docente e 10\% das matrículas em cursos na modalidade Programa Nacional de Integração da Educação Profissional com a Educação Básica, na Modalidade de Jovens e Adultos (PROEJA).

Na Tabela 1 apresentamos uma compilação das modalidades e o quantitativo de opções de cursos ofertados atualmente no IFRS, tendo como referência o Plano de Desenvolvimento Institucional (PDI/IFRS) - (2019-2023) ${ }^{4}$

\footnotetext{
${ }^{4}$ Disponível em: https://memoria.ifrs.edu.br/wp-content/uploads/sites/4/2019/07/PDI-2019-2023.pdf. Acesso em: 20 mar. 2020.
} 
Tabela 1- Quantitativo de cursos ofertados pelo IFRS - 2019

\begin{tabular}{|l|c|}
\hline \multicolumn{1}{|c|}{ Nível/Modalidade } & Total \\
\hline Educação Profissional Técnica de Nível Médio - modalidade integrada & 20 \\
\hline Educação Profissional Técnica de Nível Médio - modalidade PROEJA & 06 \\
\hline Educação Profissional Técnica de Nível Médio - modalidade subsequente & 38 \\
\hline Educação Profissional Técnica de Nível Médio - modalidade concomitante & 8 \\
\hline Educação Profissional Técnica de Nível Médio - modalidade concomitantes/Subsequentes & 2 \\
\hline Curso Superior de Tecnologia & 16 \\
\hline Curso Superior de Licenciatura & 10 \\
\hline Programa Especial de Formação Pedagógica de Docentes para a Educação Profissional & 03 \\
\hline Curso Superior de Bacharelado & 9 \\
\hline Curso de Pós-Graduação Lato sensu & 11 \\
\hline Curso de Pós-Graduação Stricto sensu & 3 \\
\hline
\end{tabular}

Fonte: Elaborado pelos autores.

Quanto à oferta de cursos, o PDI/IFRS - (2019-2023) demonstra o quanto o IFRS está empenhado no atendimento das demandas e ao disposto na legislação, bem como assumir o compromisso social para a oferta de educação pública e gratuita. No momento, o IFRS conta com 164 cursos técnicos, 81 cursos superiores e 11 cursos de pós-graduação, com aproximadamente 20.058 alunos matriculados. Entre os desafios a serem superados, destacamos a necessidade de ampliação de vagas na modalidade PROEJA e a diversificação da oferta de cursos nos campi, a fim de garantirmos a verticalização em âmbito local e/ou regional. No tocante ao ensino, o referido documento traz em seu bojo, a necessidade de fomentarmos a produção de práticas inovadoras, articulando o ensino, a pesquisa e a extensão na busca constante de aprimoramento das propostas pedagógicas. Destaca, ainda, a importância da busca da consolidação da identidade institucional mediante à intensificação de estratégias potencializadoras de interlocuções e parcerias com a sociedade (IFRS, 2019).

Visando potencializar a verticalização do ensino e, ao mesmo tempo, a qualificação das práticas educativas, no ano de 2017 foi aprovado o Mestrado Profissional em Educação Profissional e Tecnológica em Rede Nacional (ProfEPT). O Curso passou a ser ofertado na modalidade semipresencial pela RFEPCT, tendo a coordenação nacional a cargo do Instituto Federal do Espírito Santo (IFES).

Conforme previsto em Regulamento do Programa de Pós-Graduação - Mestrado ProfEPT (BRASIL, 2017), o curso tem como objetivo proporcionar formação em educação profissional e tecnológica, contribuindo para a melhoria da qualidade do ensino e para o desenvolvimento de pesquisas na área. Quanto à avaliação, o Mestrado ProfEPT está vinculado à área de Ensino da Coordenação de Aperfeiçoamento de Pessoal de Nível Superior (CAPES) do Ministério da Educação (MEC). Tanto as pesquisas quanto os produtos educacionais decorrentes dessas são disponibilizados no Catálogo de Teses e Dissertações da CAPES (Brasil, 2020) ${ }^{5}$ e no Portal de Objetos Educacionais (eduCAPES) (Brasil, 2020) ${ }^{6}$, respectivamente.

\footnotetext{
${ }^{5}$ Disponível em: https://catalogodeteses.capes.gov.br/catalogo-teses. Acesso em: 3 fev. 2020

${ }^{6}$ Disponível em: https://educapes.capes.gov.br/redirect?action=about. Acesso em: 3 fev. 2020. 
Em 11/12/2018 ${ }^{7}$ ocorreu a apresentação da primeira dissertação à banca do ProfEPT, cujo título foi $A$ Reforma do Ensino Médio e o Direito à Educação: uma Abordagem Jurídica e Contextualizada da Lei n. -13.415 de 2017. O trabalho foi defendido pela discente Marta Fagundes Dutra e orientado pelo professor Edilson Chaves, ambos do Instituto Federal do Paraná (IFPR). Até o final do ano de 2019, foram defendidas 213 dissertações desenvolvidas por pesquisadores/as integrantes das primeiras turmas de Instituições Associadas (IAs) localizadas em diferentes regiões brasileiras. A partir desse quantitativo inicial, realizamos uma pesquisa, a qual caracterizamos como de cunho qualitativo, exploratório e descritivo, tomando como base os referenciais metodológicos de Gil (2007). Optamos pelo uso da expressão "estado da arte" no título, tomando como inspiração os estudos de Romanowski e Ens, os quais definem que:

\begin{abstract}
Estados da arte podem significar uma contribuição importante na constituição do campo teórico de uma área de conhecimento, pois procuram identificar os aportes significativos da construção da teoria e prática pedagógica, apontar as restrições sobre o campo em que se move a pesquisa, as suas lacunas de disseminação, identificar experiências inovadoras investigadas que apontem alternativas de solução para os problemas da prática e reconhecer as contribuições da pesquisa na constituição de propostas na área focalizada (ROMANOWSKI; ENS, p. 39).
\end{abstract}

Em termos metodológicos, com o intuito de refinar os dados de busca, utilizamos os descritores: ensino médio integrado, interdisciplinaridade e PROEJA. Justificamos tal escolha pois tais palavras remetem a conceitos fundamentais da Educação Profissional. Eles estão presentes, tanto nas finalidades quanto nos princípios pedagógicos e compromisso social da educação profissional, e configuram a identidade institucional da RFEPCT, conforme disposto na Lei Federal n.o 11.892/2008 (Brasil, 2008). Frisamos, ainda, o fato de que, conforme dispõe a Resolução CNE n.․ 06/2012 (Brasil, 2012), a interdisciplinaridade é um dos princípios balizadores das práticas pedagógicas em tal modalidade da educação.

Art. 6o São princípios da Educação Profissional Técnica de Nível Médio:

VII -interdisciplinaridade assegurada no currículo e na prática pedagógica, visando à superação da fragmentação de conhecimentos e de segmentação da organização curricular;

VIII -contextualização, flexibilidade e interdisciplinaridade na utilização de estratégias educacionais favoráveis à compreensão de significados e à integração entre a teoria e a vivência da prática profissional, envolvendo as múltiplas dimensões do eixo tecnológico do curso e das ciências e tecnologias a ele vinculadas (BRASIL, 2012).

Ao acessarmos o site do Catálogo de Teses e Dissertações da Capes, optamos por filtrar as informações selecionando a categoria de Programa (no caso Educação Profissional e Tecnológica) e a área de avaliação pela CAPES (ensino, no qual está vinculado o Mestrado). Os dados produzidos foram catalogados em planilhas excel, nas quais registramos informações referentes às dissertações (tais como título, resumo, palavraschave e instituição associada na qual foi desenvolvida), sistematizando-as através de tabelas. Nas próximas seções, de forma sucinta, apresentamos as sistematizações e reflexões realizadas a partir deste estudo.

\footnotetext{
${ }^{7}$ Matéria publicada no site: $\mathrm{http} / / /$ portal.conif.org.br/en/component/content/article/84-ultimas-noticias/2419-realizada-primeira-banca-demestrado-do-profept, em 11/3/2018. Acesso em: 30 abr. 2020.
} 


\title{
1. O Ensino Médio InTEgrado - Contribuições das pesquisas no Mestrado ProfetP para a PROdUÇão de práticas INOVAdoras de ENSINO
}

Santomé (1998), ao abordar o conceito de currículo integrado, tece críticas às concepções de currículo escolar (re)produzidas dentro da lógica da produção de inspiração fordista e taylorista. Nessa perspectiva, os sistemas escolares passaram a reproduzir a dinâmica de funcionamento do sistema capitalista de produção com a fragmentação dos conteúdos, a instituição de políticas curriculares, as quais muitas vozes acabam sendo negadas e/ou silenciadas no âmbito das práticas escolares. Ao examinar como as mudanças históricas, sociais, econômicas e culturais da atual conjuntura repercutem na escola e, em especial, no currículo, o autor reforça a urgência de uma educação comprometida com a democracia, a solidariedade e a criticidade.

\begin{abstract}
É preciso formar pessoas com capacidade de crítica e solidariedade, se não quisermos deixá-las ainda mais indefesas. Enquanto isso, professoras, professores, estudantes e grupos sociais convencidos do valor da educação, apesar de todo tipo de obstáculos, continuarão abrindo novas brechas, desenvolvendo práticas educacionais mais democráticas, nas quais garotos e garotas pertencentes a grupos sociais não-hegemônicos não serão discriminados (SANTOME, 1998, p. 23).
\end{abstract}

Nessa mesma seara de discussões, Arroyo (2002) nos convoca a refletirmos sobre o papel da educação, a qual ele define como prática social que engloba sujeitos inseridos num determinado tempo e espaço e, portanto, marcada pela diversidade de experiências culturais dos sujeitos que dela participam. Considerando que vivemos em um mundo altamente complexo e mutante, no qual ocorrem transformações nas esferas econômicas, políticas, sociais e culturais, precisamos redimensionar as relações entre a escola e o contexto. No âmbito da educação profissional, romper com o paradigma dualista e excludente que, historicamente, pautou as políticas e as práticas educacionais, implica repensarmos a função social da escola, o que inclui o currículo, as práticas pedagógicas e avaliativas. Nessa linha de pensamento, Frigotto (2008) enfatiza a importância de aprofundarmos os estudos acerca do currículo e a relação trabalhoeducação. A atual conjuntura brasileira instiga a refletirmos sobre a função social da escola diante das juventudes expostas as mais variadas formas violências e fortemente demarcadas pela interseccionalidade entre gênero, classe social e raça. Segundo o autor,

[...] a teoria pedagógica e a relação trabalho-educação se empobrecem quando seu foco deixa de ser as pessoas, as relações sociais e passam a privilegiar as técnicas, as tecnologias, os métodos, os conteúdos inculcados. Por sua vez a pedagogia escolar se empobrece quando secundariza o peso da materialidade em que se produz a existência e se reproduzem os seres humanos. A teoria pedagógica e a relação trabalho-educação se enriquecem quando incorporam todas essas dimensões (FRIGOTTO, 2008, p.165).

No âmbito da educação profissional, o debate em torno do currículo perpassa pelos estudos e pelas propostas voltadas ao ensino médio integrado. Em termos de Brasil, entre os/as expoentes, citamos a pesquisadora Ramos (2008, 2010, 2017), cujos trabalhos tem contribuído de forma significativa para a implementação de práticas 
inovadoras. Compactuamos com o entendimento da autora de que formar profissionalmente não se restringe a preparar exclusivamente para o trabalho, mas possibilitar a compreensão das dinâmicas socioprodutivas das sociedades modernas, com as conquistas e os seus revezes, e também habilitar as pessoas para o exercício autônomo e crítico de profissões (RAMOS, 2008).

Isso posto, é preciso problematizarmos o conceito de integração, o qual significa mais do que a mera junção entre a oferta de ensino médio e a formação profissional. Conforme a estudiosa, implica relacionar, internamente à organização curricular e do desenvolvimento do processo de ensino-aprendizagem, conhecimentos gerais e específicos, cultura e trabalho, humanismo e tecnologia (RAMOS, 2010). Ao abordar o revés nas políticas educacionais para o Ensino Médio, a partir da Lei $n .$. 13.417/2017, a pesquisadora é enfática ao afirmar que defender o ensino médio integrado é defender 0 direito a uma formação humana e plena, tendo o trabalho como princípio educativo.

\begin{abstract}
A luta pelo Ensino Médio Integrado é a luta pelo direito a uma formação humana e plena, tendo o trabalho como princípio educativo em um currículo centrado nas dimensões fundamentais da vida: o trabalho, a ciência e a cultura. Por essa concepção de formação, 0 conhecimento não é, somente, um insumo ou um instrumento para o desempenho acadêmico ou profissional. Antes, o conhecimento resulta da apreensão da realidade pelos seres humanos, num processo histórico em que buscamos compreender nossas necessidades e produzir meios para satisfazê-las. Esse é o próprio processo do trabalho, o qual gera conhecimentos e novos modos de vida. Explica-se, assim, a unidade entre trabalho, ciência e cultura que fundamenta a concepção do Ensino Médio Integrado (RAMOS, 2017, p. 42).
\end{abstract}

Frente ao atual cenário educacional, proporcionar a formação integrada é o desafio posto à RFEPT, a qual busca desenvolver propostas pedagógicas que possibilitem aos estudantes o estabelecimento de conexões entre os conhecimentos historicamente construídos com a realidade em que vivem. Como mencionamos anteriormente, no âmbito da RFEPT, conforme artigos 6 e 7 da Lei com nำ11.892/2008, compete aos Institutos Federais:

Art. 7o Observadas as finalidades e características definidas no art. 60 desta Lei, são objetivos dos Institutos Federais:

I- ministrar educação profissional técnica de nível médio, prioritariamente na forma de cursos integrados, para os concluintes do ensino fundamental e para o público da educação de jovens e adultos (Brasil, 2008).

Todavia, no ano de 2007, antes mesmo da criação da RFEPT, foi lançado o Documento Base da Educação Profissional Técnica de Nível Médio Integrada ao Ensino Médio (Brasil, 2007), cujos princípios balizam a construção de propostas pedagógicas. Entre tais princípios, citamos a formação humana integral; o trabalho, a ciência, a tecnologia e a cultura como categorias indissociáveis da formação humana; o trabalho como princípio educativo; a pesquisa como princípio educativo; o trabalho de produção do conhecimento e a relação parte-totalidade na Proposta Curricular. Além disso, a oferta de Educação Profissional Integrada ao Ensino Médio remete compreendermos a natureza filosófica atribuída ao sentido de integração.

Ele expressa uma concepção de formação humana, com base na integração de todas as dimensões da vida no processo educativo, visando à formação omnilateral dos sujeitos. Essas dimensões são o trabalho, a ciência e a cultura. O trabalho compreendido como realização humana inerente ao ser (sentido ontológico) e como prática econômica (sentido histórico associado ao modo de produção); a ciência compreendida como os conhecimentos 
produzidos pela humanidade que possibilita o contraditório avanço das forças produtivas; $\mathrm{e}$ a cultura, que corresponde aos valores éticos e estéticos que orientam as normas de conduta de uma sociedade (BRASIL, 2007).

Com base em tais premissas, o Mestrado ProfEPT busca o desenvolvimento de pesquisas que contemplem as especificidades e os desafios postos à implementação da educação profissional de nível técnica, na modalidade integrada ao ensino médio. Entre as linhas de pesquisas, citamos a de Práticas Educativas em Educação Profissional e Tecnológica (EPT), que engloba os fundamentos das práticas educativas e do desenvolvimento curricular na Educação Profissional e Tecnológica em suas diversas formas de oferta, com foco nas estratégias transversais e interdisciplinares, que possibilitem formação integral e significativa do estudante, sustentados no trabalho como princípio educativo e na pesquisa como princípio pedagógico, em espaços formais e não formais (BRASIL, 2007).

Diante do exposto, investigamos no Catálogo de Teses e Dissertações da Capes (BRASIL, 2020) quais as pesquisas produzidas no âmbito do Mestrado ProfEPT, cujo foco tenha sido o ensino médio integrado. Como estratégia, inicialmente utilizamos os descritores: Ensino Médio Integrado, Interdisciplinaridade e Proeja, os quais foram escritos tanto em letras maiúsculas quanto minúsculas, a fim de verificar o reconhecimento dos caracteres pelo sistema.

Em relação ao descritor ensino médio integrado, identificamos 20 dissertações defendidas no ano de 2019 que abordaram tal temática. Entre as IAs integrantes da Rede Federal, identificamos que o IF-Goiás teve o maior número de estudos (quatro), seguido pelo IF-Paraná com três trabalhos, IF-Santa Catarina e IF-Farroupilha (dois trabalhos). Identificamos, também, uma dissertação produzida no Programa das seguintes IAs: IF-Amazonas, IF-Pernambuco, IF-Rio Grande do Sul, IF-Sergipe, IFSudoeste de Minas Gerais e IFSul. Com base nesses dados, destacamos que o tema foi abordado em 20 das IAs de um total de 38 que formam a Rede, abrangendo as diversas regiões do país.

Num segundo momento, realizamos a leitura do resumo, das palavras-chave e dos produtos disponibilizados no eduCAPES (BRASIL, 2020). Quanto ao formato de tais produtos, encontramos o que segue (Tabela 2):

Tabela 2- Produtos educacionais - descritor: Ensino Médio Integrado

\begin{tabular}{|l|c|l|}
\hline \multicolumn{1}{|c|}{ INSTITUIÇÃO ASSOCIADA (IA) } & $\begin{array}{c}\text { Quantidade } \\
\text { de produtos }\end{array}$ & \multicolumn{1}{c|}{ Formato do produto } \\
\hline IF-AMAZONAS & 1 & Avaliação institucional interna para os cursos de EPTNM \\
\hline IF-FARROUPILHA & 1 & Blog \\
\hline \multirow{4}{*}{ IF-GOIÁS } & 1 & e-book \\
\cline { 2 - 3 } & 1 & Sequência didática (SQ) \\
\cline { 2 - 3 } & 1 & Oficinas \\
\cline { 2 - 3 } & 1 & Plano de Curso de Extensão Universitária \\
\cline { 2 - 3 } & 1 & História em Quadrinhos (HQ) \\
\cline { 2 - 3 } & 1 & Guia para discentes \\
\cline { 2 - 3 } & 1 & Sequência didática (SQ) \\
\hline IF-PARANÁ & 1 & Sequência didática (SQ) \\
\hline IF-RIO GRANDE DOSUL & 1 & Sequência didática (SQ) \\
\hline \multirow{3}{*}{ IF-SANTA CATARINA } & 1 & Curso preparatório online \\
\hline \multirow{2}{*}{ IF-SÃO PAULO } & 1 & Oficinas \\
\cline { 2 - 3 } & 1 & História em Quadrinhos (HQ) \\
\cline { 2 - 3 } & 1 & Sequência didática (SQ) \\
\cline { 2 - 3 } & &
\end{tabular}




\begin{tabular}{|l|c|l|} 
& 1 & Maquete codificada \\
\hline IF-SERGIPE & 1 & Documentário \\
\hline IF-SUDESTE DE MINAS & 1 & Manual da Comissão de Permanência e Êxito \\
\hline IF-SUL-RIO-GRANDENSE & 1 & Minicooperativa como ferramenta pedagógica \\
\hline
\end{tabular}

Fonte: Elaborado pelos autores.

Ao realizarmos a leitura das dissertações acima citadas, destacamos alguns pontos em comum entre elas, tais como a participação maciça de estudantes nos processos de pesquisa, os quais culminaram na produção e validação dos produtos. Outro fator evidenciado é que tais propostas foram desenvolvidas com foco no aprimoramento das práticas pedagógicas desenvolvidas, majoritariamente, no contexto da educação profissional ofertada nas diversas IAs. O estudo aponta, ainda, a variedade de produtos educacionais, incluindo as sequências didáticas que apresentam estratégias e recursos diversificados.

Destacamos a relevância das pesquisas desenvolvidas, as quais trazem contribuições significativas para a implementação de propostas pedagógicas no âmbito do ensino médio integrado, fornecendo subsídios teóricos e metodológicos para a implementação de práticas de ensino que estejam em consonância com as demandas. Isso posto, ressaltamos a importância de compartilharmos tais experiências e fomentarmos o desenvolvimento de outras no âmbito da Rede Federal, em particular, no Mestrado Profissional, foco da presente análise.

\section{A PRODUÇÃO DE PROPOSTAS INTERDISCIPLINARES DE ENSINO NO ÂMBITO DO Mestrado Profissional Profept}

Entre os/as autores/as que discutem o conceito de interdisciplinaridade, Japiassu (1976, 1994) enfatiza que a característica central é a incorporação de diversas áreas de conhecimento, tomando-lhes de empréstimo esquemas conceituais de análise, a fim de fazê-los integrar, depois de havê-los comparado e julgado. Entre as contribuições, cita a troca de informações entre as disciplinas, reorganizando os processos científicos, ampliando a formação geral de todos os envolvidos. Tais práticas fornecem instrumentos conceituais e, ao mesmo tempo, demonstram os limites metodológicos de cada especialista, suscitando o diálogo com os demais. Entretanto, o autor chama a atenção para o fato de que a interdisciplinaridade não é uma simples reunião, adição ou coleção de várias especialidades. Também não se resume a uma simples tomada de posição teórica de especialistas que se encontram reunidos e justapostos por razões que não tem muito a ver com o interesse da pesquisa. Conforme Japiassu, a interdisciplinaridade implica, acima de tudo, coragem para romper barreiras institucionais e/ou conceituais a partir de práticas pautadas no diálogo e na ousadia.

[...] ter a coragem de, todo dia, dizer a seguinte oração: Fome nossa de cada dia nos dai hoje; ter a coragem de devolver, à sua razão, sua função turbulenta e agressiva; ter a coragem de, no domínio do pensamento, fazer da imprudência um método; saber colocar questões, não buscar respostas; não perguntar ou pensar antes de estudar; estar consciente de que ninguém se educa com idéias ensinadas; não ousar fazer experiências que não sejam iluminadas pela razão, porque, do contrário, elas não merecem ser tentadas; ter coragem de sempre fornecer à sua razão, razões para mudar; não cultivar o gosto pelo porto seguro ou pela certeza do sistema, porque nosso conhecimento nasce da dúvida e se alimenta de incertezas (JAPIASSU, 1994, p. 3).

Para Santomé (1998), a interdisciplinaridade pode ser definida enquanto um processo e uma filosofia de trabalho que se faz de acordo com a hora de enfrentar problemas e 
questões que preocupam cada sociedade. O autor enfatiza que não há um processo único, muito menos uma linha rígida de ações para que possamos pensar uma prática interdisciplinar.

Em suas pesquisas, Pombo (2008) destaca o caráter polissêmico e multifacetado da palavra interdisciplinaridade, cujo entendimento implica transpormos o paradigma cartesiano das ciências no âmbito de nossas práticas educativas. Isso, por sua vez, requer repensarmos a própria concepção de ciência uma vez que estamos imersos num mundo cada vez mais globalizado, cujas fronteiras tem sido transpostas, inclusive no âmbito do processo de produção e difusão de conhecimentos.

\begin{abstract}
Estamos, portanto, na situação de termos necessidade de alargar o próprio conceito de interdisciplinaridade. Já tivemos que alargar o conceito de ciência, já tivemos que passar de uma ciência que era predominantemente analítica para uma ciência que, atenta às novas complexidades que constantemente descobre e inventa, procede cada vez mais de forma transversal. Temos de perceber que estamos num mundo em que os muros foram derrubados (embora outros estejam a ser erguidos, a queda do muro de Berlim é um acontecimento de inesgotável sentido simbólico). Estamos num mundo de anulação e de mistura de fronteiras. Como diz Agamben (1990), a comunidade que vem é uma comunidade de imigrantes, de mestiços, de apátridas, de impuros, de sem-terra. O que nos espera é um mundo em que se perde o próprio sentido da identidade (ou seria melhor dizer, de pertença a um lugar?). Esta é também uma realidade nova que exige de nós a capacidade para encontrar formas mais alargadas de pensar e que, muito provavelmente, tem a ver com as questões que se dão a pensar sob a palavra interdisciplinaridade (POMBO, 2008, p. 24).
\end{abstract}

Em consonância com os debates acima apresentados, as análises realizadas por Fazenda (2008) e Trindade (2008) convergem no entendimento de que mais do que a inserção da palavra no cotidiano pedagógico, a interdisciplinaridade remete para uma mudança de atitudes no âmbito das práticas de ensino.

Mais importante que conceituar é refletir a respeito de atitudes que se constituem como interdisciplinares. A dificuldade na sua conceituação surge porque ela está pontuada de atitudes, e não simplesmente em um fazer. Entretanto, precisa ser bem compreendida para que não ocorram desvios na sua prática, o que me levou a refletir sobre as reivindicações que a geraram e sobre suas origens. Isto é um exercício fascinante, já que ela pavimentou o caminho para outra nova ordem de se pensar o ser humano, o mundo e as coisas do mundo; velhos caminhos há muito esquecidos foram reabertos e, além disso, permitiu rever conceitos e certezas cristalizados na mente humana e viajar no tempo (TRINDADE, 2008, p. 66).

Nesse enfoque, o objetivo do mapeamento foi analisar em que medida tal temática tem sido pautada nas pesquisas realizadas no âmbito do Mestrado Profissional ProfEPT. Para tanto, utilizamos o descritor interdisciplinaridade para a busca das dissertações disponibilizadas no repositório da CAPES e dos produtos decorrentes dessas, os quais estão listados abaixo (Tabela 3).

Tabela 3 - Produtos educacionais - descritor: Interdisciplinaridade.

\begin{tabular}{|l|c|l|}
\hline \multirow{2}{*}{ INSTITUIÇÃO ASSOCIADA (IA) } & $\begin{array}{c}\text { Quantidade } \\
\text { de produtos }\end{array}$ & \multicolumn{1}{c|}{ Formato do produto } \\
\hline IF-FARROUPILHA & 1 & Projeto Interdisciplinar \\
\hline IF-PERNAMBUCO & 1 & Sequência Didática (SQ) \\
\hline IF-SUDESTE DE MINAS & 1 & Sequência Didática (SQ) \\
\cline { 2 - 3 } & 1 & Curso de extensão \\
\hline IF-SÃO PAULO & 1 & $\begin{array}{l}\text { Projeto interdisciplinar sobre o eixo temático "relações de } \\
\text { trabalho" }\end{array}$ \\
\hline
\end{tabular}

Trabalho \& Educação | v.29 | n.2 | p.183-196 | maio-ago. | 2020 
Fonte: Elaborado pelos autores.

O número relativamente baixo de produções sobre a temática da interdisciplinaridade demonstra a importância de continuarmos intensificando os estudos, ao mesmo tempo, a urgência de tal debate no âmbito da RFEPT. Por outro lado, os produtos analisados demonstram e trazem subsídios relevantes para que outras iniciativas sejam desenvolvidas em outros contextos das IAs participantes. A análise das pesquisas demonstra o potencial da Educação Profissional Integrada ao Ensino Médio enquanto campo fértil para o desenvolvimento de práticas interdisciplinares voltadas à formação integral de jovens e adultos. A articulação entre diferentes áreas de conhecimento e o protagonismo dos estudantes foi um diferencial observado nas pesquisas analisadas e que poderão inspirar outras iniciativas em diferentes contextos.

\section{O PROEJA em pauta nas pesquisas no Âmbito do Mestrado Profissional em Educação Profissional, Técnica e Tecnológica}

O PROEJA foi instituído pelo Decreto Lei n. 5.840/2006 (BRASIL, 2006) e visa à integração da educação profissional com à formação geral.

1ㅇ O PROEJA abrangerá os seguintes cursos e programas e educação profissional:

I - formação inicial e continuada de trabalhadores; e

II - educação profissional técnica de nível médio.

$\S 2^{\circ}$ Os cursos e programas do PROEJA deverão considerar as características dos jovens e adultos atendidos; e poderão ser articulados:

I - ao ensino fundamental ou ao ensino médio; objetivando a elevação do nível de escolaridade do trabalhador; no caso da formação inicial e continuada de trabalhadores (BRASIL, 2016).

A premissa básica do PROEJA é a indissociabilidade entre formação geral e profissional com a prioridade de atendimento a estudantes/trabalhadores, na perspectiva de sua formação humana e inserção ou reinserção social e laboral qualificada. Portanto, o Programa busca aproximar-se das reivindicações das classes populares que almejam a elevação da escolaridade com a formação profissional. É um marco de uma política pública de aproximação entre escolarização e profissionalização e de ampliação do acesso e da permanência de jovens e adultos à educação básica. Em outras palavras, o PROEJA reúne as condições necessárias, enquanto campo de conhecimento em construção, em suas dimensões epistemológicas e curriculares, para construção de práticas pedagógicas que possibilitem a aprendizagem interdisciplinar. Todavia, entre os desafios postos à implementação do Programa, os estudos realizados por Moura e Henrique ressaltam que:

Um dos grandes desafios do Programa é integrar três campos da educação que historicamente não estão muito próximos: o ensino médio; a formação profissional técnica de nível médio e a educação de jovens e adultos. Igualmente desafiante é conseguir fazer com que as ofertas resultantes do Programa efetivamente contribuam para a melhoria das condições de participação social, política, cultural e no mundo do trabalho desses coletivos, em vez de produzir mais uma ação de contenção social (MOURA; HENRIQUE, 2012, p. 16).

Aliado às questões acima, citam a carência de docentes formados especificamente para atuação nesse campo do ensino. Há, ainda, as desconfianças e a visão elitista de parte de profissionais que integram a Rede Federal de Ensino que vinculam o Programa a uma suposta ameaça à qualidade do ensino, os elevados índices de evasão discente e 
as barreiras a serem transpostas para alcançar o ensino integral. Outro fator a ser considerado é o uso de materiais e de metodologias que desconsideram a especificidade dos estudantes jovens ou adultos, e que acabam sendo barreiras na implementação do ensino médio integrado. Visando à superação dos obstáculos elencados, torna-se fundamental a formação inicial e continuada de docentes que atuam em tal etapa, bem como a adoção de estratégias de ensino pautadas na interdisciplinaridade e no protagonismo dos estudantes.

Considerando que o foco do Mestrado Profissional ProfEPT é a produção de práticas inovadoras de ensino, o objetivo deste estudo foi investigar em que medida o PROEJA tem sido abordado nas pesquisas. No total, localizamos somente sete, desenvolvidas em diferentes IAs, conforme demonstramos na Tabela 4.

Tabela 4- Produtos educacionais - descritor: PROEJA.

\begin{tabular}{|l|c|l|}
\hline \multicolumn{1}{|c|}{ INSTITUIÇÃO ASSOCIADA (IA) } & Produtos & \multicolumn{1}{c|}{ Formato do produto } \\
\hline \multirow{2}{*}{ IF-PARANÁ } & 1 & $\begin{array}{l}\text { Projeto Pedagógico do Curso de Aperfeiçoamento em curso do } \\
\text { PROEJA: Aspectos Teóricos e Metodológicos }\end{array}$ \\
\hline IF-PERNAMBUCO & 1 & Jogo de Role Playing Game (RPG) \\
\hline \multirow{2}{*}{ IF-RIO GRANDE DO NORTE } & 1 & Sequência Didática (SQ) \\
\cline { 2 - 3 } & 1 & Sequência Didática (SQ) \\
\hline IF-SANTA CATARINA & 1 & Sequência Didática (SQ) \\
\hline IF-SÃO PAULO & 1 & Revista PROEJA \\
\cline { 2 - 3 } & 1 & Sequência Didática (SQ) \\
\hline
\end{tabular}

Entre os dados relevantes na leitura das dissertações, destacamos a importância da escuta atenta, o olhar sensível dos/as pesquisadores/as, bem como a relevância social de tais pesquisas, o que nos remete a Dayrell, o qual enfatiza que:

Analisar a escola como espaço sócio-cultural significa compreendê-la na ótica da cultura, sob um olhar mais denso, que leva em conta a dimensão do dinamismo, do fazer-se cotidiano, levado a efeito por homens e mulheres, trabalhadores e trabalhadoras, negros e brancos, adultos e adolescentes, enfim, alunos e professores, seres humanos concretos, sujeitos sociais e históricos, presentes na história, atores na história. Falar da escola como espaço sócio-cultural implica, assim, resgatar o papel dos sujeitos na trama social que a constitui, enquanto instituição (DAYRELL, 1996, 136-137).

Cabe lembrar que, conforme Moll (2010), o Proeja enquanto política pública surge da necessidade de uma resposta à exclusão de jovens e adultos, o que nos remete a repensarmos as práticas pedagógicas, em particular, desenvolvidas no âmbito da Educação Profissional no contexto da Rede Federal. Nas palavras da autora, implica um novo paradigma epistemológico com desdobramentos pedagógicos e curriculares até a modificação do olhar em relação a essa população, em geral, invisíveis, no cotidiano escolar.

No âmbito do Mestrado ProfEPT, identificamos que até o presente momento há um número reduzido de dissertações defendidas que tenham enfocado o PROEJA. Ao realizamos a leitura das pesquisas já finalizadas, deparamos-nos com propostas de ensino que contemplam temáticas diversas (por exemplo, consumo, uso de tecnologias, ensino através da música, ética ambiental, entre outras). Cada produto é fruto do engajamento das comunidades educativas envolvidas, oriundas da participação individual e coletiva em todas as etapas, desde o planejamento até o desenvolvimento das práticas, as quais são pautadas pelo diálogo. Apesar disso, reforçamos a necessidade de ampliação de pesquisas com as temáticas aqui apresentadas, as quais 
estão no cerne das discussões, tanto nas bases conceituais da Educação Profissional quanto no Mestrado Profissional ProfEPT.

\section{CONSIDERAÇÕES FINAIS}

A imersão no universo das pesquisas na área de ensino, desenvolvidas no âmbito do Mestrado Profissional em Educação Profissional, Técnica e Tecnológica nos convoca a refletirmos sobre a educação profissional e os seus desafios no contexto atual. Consiste, também, em um momento de compartilharmos experiências inovadoras na área de ensino e em um momento para repensarmos a função social da educação e as atuais políticas públicas. Os desafios são enormes, haja visto que estamos imersos em um mundo cada vez mais competitivo e pautado por políticas neoliberais, nas quais a formação fica restrita à mera instrumentalização para o mercado de trabalho. Contudo, a análise das pesquisas desenvolvidas demonstra o quanto a escola pública se faz necessária para que jovens e adultos possam atuarem enquanto protagonistas de suas próprias vidas.

Inicialmente, a proposta era realizarmos a leitura dos resumos dos trabalhos previamente selecionados, mas no decorrer da pesquisa fomos instigados e desafiados a aprofundarmos o estudo. Contudo, ao acessarmos na íntegra o conteúdo das dissertações e os produtos oriundos dessas, constatamos o envolvimento de estudantes, docentes, gestores e demais trabalhadores/as, em diferentes contextos educativos (escolares ou não escolares). No que tange aos instrumentos de avaliação e validação, evidenciamos o quanto a pesquisa, enquanto princípio educativo, potencializa propostas educativas pautadas no protagonismo estudantil e em aprendizagens compartilhadas. Exemplo disso são as inúmeras estratégias utilizadas, tais como documentários, blogs, oficinas, sequências didáticas, entre outras, as quais resultam de um processo democrático, o qual, ao mesmo tempo, articula e transcende as diversas áreas de conhecimento, proporcionando uma formação humana integral.

Com base nos dados produzidos, reiteramos a importância de promovermos maior visibilidade das práticas de ensino no âmbito da Educação Profissional, a fim de compartilharmos, inspirarmos e fomentarmos a adoção de outras em diferentes contextos educativos. Por fim, o estudo aponta para a necessidade e a urgência de ampliarmos o rol de pesquisas, em especial, na área do ensino, no âmbito da educação profissional, contribuindo, assim, para uma formação onmilateral para jovens e adultos em diferentes contextos educativos.

No tocante ao uso de HQs, convém destacar que, desde sua origem, trazem em seu bojo temas que estão presentes em determinados contextos históricos e culturais, possibilitando ao/a leitor/a a apropriação e a ampliação de conhecimentos em diferentes áreas. Destaca-se ainda que, na atualidade, os HQs são produzidos e veiculados em diferentes contextos e (re)produzem as culturais contemporâneas, em particular, as culturas juvenis. Com o advento das tecnologias digitais que ampliam as possibilidades de produção com o uso de recursos digitais na diagramação e na editoração quanto para a difusão em diferentes plataformas (redes sociais, sites, blogs, entre outros). Todavia, nos espaços escolares, o uso de HQs, enquanto estratégia para o ensino, requer a ampliação de estudos, a fim de potencializar as possibilidades de uso de forma a oportunizar aprendizagens significativas e apropriação de conceitos, em especial, por 
jovens e adultos. Nesse enfoque, destacamos a relevância e a necessidade de ampliarmos os estudos sobre a utilização das HQs enquanto estratégia de ensino, em especial, no âmbito das práticas educativas da educação profissional.

\section{REFERÊNCIAS}

ARROYO, Miguel. Ofício de mestre: imagens e auto-imagens. Petrópolis, RJ: Editora Vozes, 2002.

BRASIL. Decreto n. 5.154 de 23 de julho de 2004. Regulamenta o $§ 2^{\circ}$ do art. 36 e os arts. 39 a 41 da Lei no 9.394, de 20 de dezembro de 1996, que estabelece as diretrizes e bases da educação nacional, e dá outras providências. Brasília - DF: 2004. Disponível em: http:/www.planalto.gov.br/ccivil_03/_ato20042006/2004/decreto/d5154.htm. Acesso em: 5 dez. 2019.

BRASIL. Decreto n. 5.840 de 13 de julho de 2006. Institui, no âmbito federal, o Programa Nacional de Integração da Educação Profissional com a Educação Básica na Modalidade de Educação de Jovens e Adultos - PROEJA, e dá outras providências. Brasília, DF: Presidência da República, 2006. Disponível em: http://www.planalto.gov.br/ccivil_03/_Ato2004-2006/2006/Decreto/D5840.htm. Acesso em: 5 dez. 2019.

BRASIL. Educação Profissional Técnica de nível Média Integrada ao Ensino Médio. Documento Base. Brasília: Ministério da Educação, 2007. Disponível em: http://portal.mec.gov.br/setec/arquivos/pdf/documento__base.pdf. Acesso em: 5 dez. 2019.

BRASIL. Lei n.o 11.892, de 29 de dezembro de 2008. Institui a Rede Federal de Educação Profissional, Científica e Tecnológica, cria os Institutos Federais de Educação, Ciência e Tecnologia, e dá outras providências.

BRASIL. Resolução n. 6, de 20 de dezembro de 2012. Diretrizes Curriculares Nacionais para a Educação Profissional Técnica de Nível Médio. Brasília - DF, 2019. Disponível em: http://portal.mec.gov.br/index.php?option=com_docman\&view=download\&alias=11663-rceb006-12pdf\&category_slug=setembro-2012-pdf\&ltemid=30192. Acesso em: 5 dez. 2019.

BRASIL. Regulamento do Mestrado ProfEPT. Instituto Federal de Educação, Ciência e Tecnologia. 2017. Disponível em: http://profept.ifes.edu.br/regulamentoprofept. Acesso em: 5. fev. 2020.

BRASIL. Plataforma Sucupira. Ministério da Educação, Brasília, 2018. Disponível em: https://sucupira.capes.gov.br/sucupira. Acesso em: 9 fev. 2020.

BRASIL. Plataforma Nilo Peçanha. Ministério da Educação, Brasília, 2020. Disponível em: http://plataformanilopecanha.mec.gov.br/. Acesso em: 9 fev. 2020.

BRASIL. Portal de Portal de Objetos Educacionais da CAPES - eduCAPES. Coordenação de Aperfeiçoamento de Pessoal de Nível Superior, Brasília, DF, 2020. Disponível em: https://www.periodicos.capes.gov.br/index.php?option=com_pcontent\&view=pcontent\&alias=historico\&ltem id=157. Acesso em: 9 fev. 2020.

DAYRELL, Juarez. A Escola como Espaço Sócio-Cultural. In: DAYRELL, Juarez (Org.). Múltiplos Olhares: sobre educação e cultura. Belo Horizonte: UFMG, 1996.

FAZENDA, Ivani Catarina Arantes (Org.). Que é interdisciplinaridade? São Paulo, SP:Cortez, 2008.

FAZENDA, Ivani Catarina Arantes. Interdisciplinaridade: história, teoria e pesquisa. 18. ed. Campinas, SP: Papirus, 2012.

FRIGOTTO. Gaudêncio.A interdisciplinaridade como necessidade e como problema nas Ciências Sociais. Revista do Centro de Educação e Letras. UNIOESTE, Campus Foz do Iguaçu, v. 10, n. 1, p. 41 - 62, $1^{\circ}$ sem./2008.

FRIGOTTO, Gaudêncio; CIAVATTA, Maria Aparecida; RAMOS, Marise. Ensino médio integrado: concepção e contradições. São Paulo: Cortez, 2005.

FRIGOTTO, Gaudêncio. Educação e crise do trabalho: perspectivas de final de século. Petrópolis: Vozes, 2008. 
JAPIASSÚ, Hilton. Interdisciplinaridade e Patologia do Saber. Rio de Janeiro: Imago, 1976.

JAPIASSÚ, Hilton. A questão da interdisciplinaridade. Porto Alegre: Secretaria Municipal de Educação de Porto Alegre, 1994 . Disponível em: http://smeduquedecaxias.rj.gov.br/nead/Biblioteca/Forma\%C3\%A7\%C3\%A30\%20Continuada/Artigos\%20Diversos/interdisciplinaridade-japiassu.pdf.

Acesso em: 5 dez. 2019.

SANTOMÉ, Jurjo Torres. Globalização e interdisciplinaridade - o currículo integrado. Porto Alegre: Artes Médicas, 1998.

IFRS. Instituto Federal de Educação, Ciência e Tecnologia do Rio Grande do Sul. Plano de Desenvolvimento Institucional (PDI) do IFRS - 2019-2023. Disponível em: https:/ifrs.edu.br/wpcontent/uploads/2019/03/PDI-FINAL-2018_Arial.pdf. Acesso em: 3 fev. 2020.

MOURA, Dante Henrique. Ensino médio integrado: subsunção aos interesses do capital ou travessia para a formação humana integral. Educação e Pesquisa. São Paulo, v. 39, n. 3, p. 705-720, jul/set. 2013.

MOURA, Dante Henrique; HENRIQUE, Ana Lúcia Sarmento. Proeja: entre desafios e possibilidades. Revista HOLOS. Natal, ano 28, v. 2, p. 114 - 129, mai. 2012.

POMBO, Olga. Epistemologia da interdisciplinaridade. Ideação-Revista do Centro de Educação e Letras da Unioeste. Foz do Iguaçu, v. 10, n. 1, p. 9-40, 2008. Disponível em:

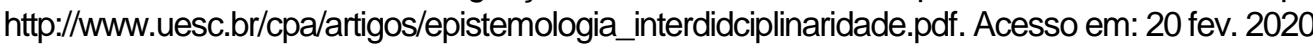

RAMOS, Marise. Concepção do ensino médio integrado. 2008. Disponível em: http://forumeja.org.br/go/sites/forumeja.org.br.go/files/concepcao_do_ensino_medio_integrado5.pdf.

Acesso em: 3 dez. 2019.

RAMOS, Marise. Ensino Médio Integrado: ciência, trabalho e cultura na relação entre educação profissional e educação básica. In: MOLL, Jaqueline et. al. Educação profissional e tecnológica no Brasil Contemporâneo: desafios, tensões e possibilidades. Porto Alegre: Artmed, 2010.

RAMOS, Marise. Ensino Médio Integrado: lutas históricas e resistências em tempos de regressão. In: ARAUJO, Adilson Cesar; SILVA, Claudio Nei Nascimento da (Orgs.). Ensino Médio Integrado no Brasil: fundamentos, práticas e desafios/. Brasília: Ed. IFB, 2017. 569 p.

ROMANOWSKI, Joana Paulin; ENS, Romilda Teodora. As pesquisas denominadas do tipo "estado da arte" em educação. Revista Diálogo Educacional, Curitiba: PUC-PR, vol. 6, n. 19, set./dez., p. 37-50, 2006. Disponível em: http://redalyc.uaemex.mx/redalyc/pdf/1891/189116275004.pdf. Acesso em: 5 dez. 2019.

SANTOMÉ, Jurjo Torres. Globalização e interdisciplinaridade - o currículo integrado. Porto Alegre: Artes Médicas, 1998.

TRINDADE. Diamantino Fernandes. Interdisciplinaridade: um novo olhar sobre as ciências. In: FAZENDA, Ivani Catarina Arantes (Org). Que é interdisciplinaridade? São Paulo, SP:Cortez, 2008. p. 65-84.

Data da submissão: $14 / 04 / 2020$

Data da aprovação: 19/08/2020 